\title{
Hypoxemia During One-Lung Ventilation: Does it Really Matter?
}

\author{
Ulrich Limper $^{1,2} \cdot$ Burkhard Hartmann ${ }^{1}$
}

Published online: 7 November 2019

(C) Springer Science+Business Media, LLC, part of Springer Nature 2019

\begin{abstract}
Purpose of Review The human system of oxygen transport and metabolism is complex, and appropriate means to follow its single steps intraoperatively do not exist. Intraoperative tissue hypoxia is one of the leading dangers for patients receiving onelung ventilation (OLV). Pulmonary, cerebral, or cardiac injuries may be the result. To summarize the current knowledge about the tolerable human limits of hypoxia, inside and outside the thoracic surgery room, is the purpose of this review.

Recent Findings High altitude mountaineers and apnea divers teach us that the healthy human body is able to acclimatize to and cope with severe hypoxemia to prevent fatal tissue hypoxia. The patients receiving OLV for thoracic surgery, however, are lacking adequate time for hypoxic acclimatization. Chronical medical conditions and effects of anesthesia prevent them further from exploiting their full hypoxia defense capacity. Controlled outcome studies on hypoxemia during OLV do not exist.

Summary Patients are no mountaineers. Thus, prevention of tissue hypoxia by avoiding relevant hypoxemia must be still the major goal during OLV. However, if permissive hypoxemia as a protection against perioperative oxygen stress could be tolerable in highly selected patients is the objective of current research.
\end{abstract}

Keywords Human limit of hypoxia $\cdot$ Acclimatization - Thoracic surgery $\cdot$ Thoracic anesthesia Permissive hypoxemia . Intraoperative hypoxia

\section{Introduction}

Although non-intubated thoracoscopic surgery is currently being re-invented for minor thoracic procedures [1,2], one-lung ventilation (OLV) in thoracic surgery is still the gold standard to improve access to the operational field. During the procedure, one lung is collapsed and not ventilated, though the perfusion through the non-ventilated lung is partly continuing resulting in a significant intrapulmonary shunt of nonoxygenated blood to a maximal extent of approximately $65 \%$ of the cardiac output [3]. This shunt, amongst others,

This article is part of the Topical Collection on Thoracic Anesthesia

Ulrich Limper

limperu@kliniken-koeln.de

1 Department of Anesthesiology and Intensive Care Medicine, Merheim Medical Center (CMMC), Witten/Herdecke University, Witten, Germany

2 German Aerospace Center (DLR), Institute of Aerospace Medicine, Cologne, Germany can result in a relevant hypoxemia in up to $10 \%$ of the procedures, rather arbitrarily defined as a decrease in arterial oxygen saturation $\left(\mathrm{SaO}_{2}\right)$ of the patient blood below $90 \%$ while being ventilated with a inspiratory oxygen fraction $\left(\mathrm{FiO}_{2}\right)$ equal or greater than $0.5[4 \cdot \bullet, 5 \bullet]$. However, if this $\mathrm{SaO}_{2}$ threshold always indicates a life-threatening situation for the patient has to be questioned [6]. Nevertheless, it is not surprising that the rate of hypoxemia during one-lung ventilation is substantially higher as compared with a $1.9 \%$ hypoxemia rate, reported for a general surgical collective [7].

Hypoxemia during one-lung ventilation predominantly caused by pronounced shunting is generally difficult to treat [8]. The treatments of choice are either to re-inflate the operated lung or to raise the inspiratory oxygen fraction of the ventilated lung towards 1.0. However, intraprocedural reinflation of the operated lung impairs the access for the surgeon to the operational field and may reduce the success of surgery. As alternative or rather supplemental approaches either intermittent positive airway pressure [9-11] or differential lung ventilation [12] can be applied to the dependent lung. The extra amount of oxygen in the non-ventilated lung boosts the oxygen content in the shunt. 
Though, excessively the raising of intraoperative $\mathrm{FiO}_{2}$ with the intention to treat hypoxemia means to replace one evil by another. Oxygen is a powerful vasoconstrictor and the paradoxical situation may arise that hyperoxia (increased arterial oxygen partial pressure) leads to a reduced oxygen delivery to the vascular beds of various organs, especially of the brain or heart [13••]. Moreover, hyperoxia results in increased oxygen stress of the body and in particular of the lungs, resulting in the increased generation of resorption atelectasis $[14,15]$. The increase of perioperative oxygen stress is furthermore caused by the generation of reactive oxygen species (ROS) and leads to molecular, cell, and organ damage [16]. However, it has been argued that ROS are not bad as a matter of principle but can be considered beneficial at low to moderate concentrations [17•]. Nevertheless, an increased perioperative risk for cardio-pulmonary complications and for a worse outcome was found in patients who underwent cancer surgery and received a high intraoperative oxygen therapy $[18,19]$.

Intraoperative oxygen stress represents harm both to the ventilated and predominantly to the collapsed lung and may finally lead to the acute respiratory distress syndrome (ARDS). At the end of the OLV procedure, an ischemiareperfusion syndrome arises in the collapsed lung which is characterized by pathological capillary leakage and increased rates of leukocyte and platelet activation [20-23]. High inspiratory oxygen fractions, hyperoxemia, and hyperoxia are all known to aggravate the organ damage caused by an ischemiareperfusion syndrome and should therefore be avoided as much as possible by the treating anesthesiologist.

Surgical procedures including OLV are in particular associated with a liberal oxygen therapy regime [24•]. A generally accepted minimum of $\mathrm{SaO}_{2}$ below which hypoxemia appears has not been defined and the tolerable limits of hypoxemia during OLV of patients receiving thoracic surgery are not really known. In daily clinical work, the anesthesiologist is left to his own experience regarding at which $\mathrm{SaO}_{2}$ he thinks hypoxemia starts to threaten his patient. He has to decide how far he accepts the $\mathrm{SaO}_{2}$ to fall and at which level of hypoxemia, resistant to any therapy, he requests to adjourn or to stop the surgical procedure.

\section{The Clinical Case}

A male, 57-year-old, smoking (45 pack years) individual, who was free of other relevant medical conditions, suffered from a B2 thymoma with an UICC stadium IV-A. The large tumor mass in the left mediastinum infiltrated the left brachiocephalic vein leading to occlusion of the vessel and the generation of a distinct net of venous collaterals Fig. 1a. Furthermore, the tumor infiltrated the right cardiac ventricle. In a polysomnographic sleep study performed as part of the preoperative evaluation, the patient showed phases of desaturation to a $\mathrm{SO}_{2}$ minimum of $80 \%$. On day of surgery, the patient received a thoracic epidural catheter and continuous epidural anesthesia was maintained with $1.8 \mathrm{mg} / \mathrm{h}$ ropivacaine and $1.2 \mu \mathrm{g} / \mathrm{h}$ sufentanil throughout the whole procedure. Total intravenous general anesthesia was induced intravenously with $200 \mathrm{mg}$ propofol, $30 \mu \mathrm{g}$ sufenanil, and $50 \mathrm{mg}$ rocuronium and maintained with $4-8 \mathrm{mg} / \mathrm{kg} / \mathrm{h}$ propofol, sufentanil, and rocuronium. The patient was intubated with a 37-French right-sided double lumen tube. One-lung ventilation of the right lung was performed during two subsequent phases throughout the course of the procedure. $\mathrm{FiO}_{2}$ was always maintained between 0.9 and 1.0.

The resection of the tumor took place in supine position via a median sternotomy in combination with a left lateral thoracotomy. The large tumor mass for the most part, together with the left brachiocephalic vein and the left upper pulmonary lobe, could be removed. A pericardial patch was inserted into the superior cava vein.

The surgical procedure led to an extreme blood loss of approximately $24 \mathrm{~L}$ which required a mass transfusion of 36 units of packed red cells, 16 units of fresh-frozen plasm, two units of platelets, and $30 \mathrm{~L}$ of crystalloid fluids. Moreover, a continuous infusion of up to $1 \mu \mathrm{g} / \mathrm{kg} / \mathrm{min}$ norepinephrine was necessary to maintain a circulation at least on a minimal level Fig. $1 b$.

Due to the circulatory instability of the patient, the tumor could not be fully removed and hypoxic harm to the brain of the patient caused by the simultaneous appearance of hypoxemic, anemic, and stagnant hypoxias was expected Fig. 1c. Following the procedure, the patient developed a strong systemic inflammatory response syndrome with a subsequent acute delirium. Surprisingly the patient recovered fast and was discharged from the hospital 1 month later without any cognitive sequela. However, the patient reported a significant vision loss of his right eye which had newly occurred after the procedure. A detailed ophthalmological examination revealed occurrence of a bilateral anterior ischemic optic neuropathy (AION). A therapeutically attempt with $1000 \mathrm{mg}$ decortine was not successful. A postoperative computer tomographic angiographic scan of the head was free of any stenosis of the cerebral arteries and showed a regular brain parenchyma without any signs of stroke.

\section{Tolerable Limits of Hypoxia}

\section{General Physiological Aspects of the Oxygenation of the Human Body}

This case report begs the question of the tolerable limits of hypoxia in patients receiving a thoracic surgical procedure. Whereas this question can be easily answered for the healthy, conscious individual, it is difficult to give a satisfying answer 
a

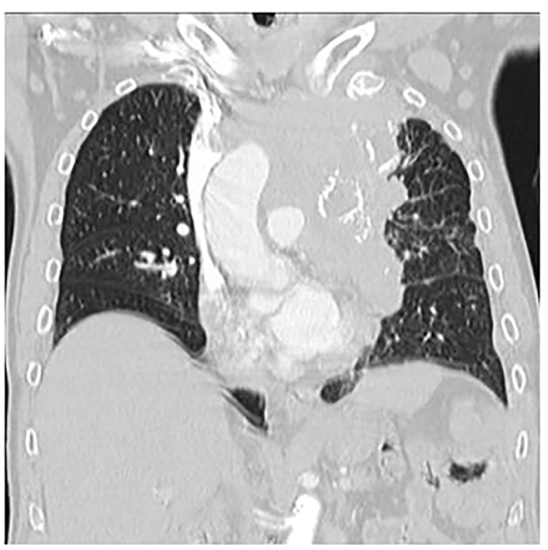

b

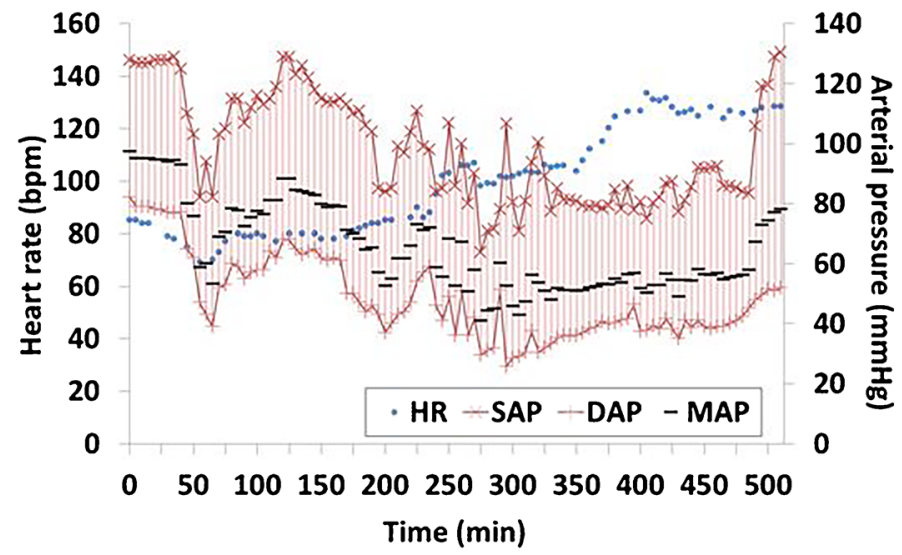

\begin{tabular}{|c|c|c|c|c|c|c|c|c|}
\hline \multirow[t]{2}{*}{ C } & \multicolumn{8}{|c|}{ Blood gas (intraoperative minute) } \\
\hline & 60 & 180 & 240 & 270 & 300 & 330 & 450 & Post surgery \\
\hline $\mathrm{SaO2}(\%)$ & 100 & 100 & 91 & 74 & 96 & 71 & 100 & 96 \\
\hline $\mathrm{PaO2}(\mathrm{mmHg})$ & 264 & 299 & 67 & 50 & 105 & 51 & 290 & 83 \\
\hline $\mathrm{Hb}(\mathrm{g} / \mathrm{dl})$ & 10.9 & 5.8 & 6.5 & 7.8 & 9.5 & 9.5 & 5.1 & 10.9 \\
\hline $\mathrm{CaO} 2(\mathrm{ml} / \mathrm{dL})$ & 16.0 & 9.0 & 8.4 & 8.2 & 13.0 & 9.5 & 8.0 & 14.8 \\
\hline Lactate (mmol/L) & 0.4 & 0.4 & 1.6 & 2.2 & 4.2 & 2.0 & 2.6 & 1.3 \\
\hline Base exzess (mmol/L) & 2.2 & -1.2 & 0.1 & -6.2 & -6.9 & -7.2 & -3.1 & 0.5 \\
\hline
\end{tabular}

Fig. 1 a A computer tomographic scan with contrast agent of the thorax showing a mass (thymome) localized predominantly in the upper and medial left mediastinum. The tumor spreads into the left pleural cave and infiltrates the left brachiocephalic vein and the superior cava vein. b The intraoperative circulatory profile is showing a phase of prolonged arterial hypotension during the second half of the procedure (red upper

for the individual with pre-existing medical conditions undergoing a thoracic surgical procedure. In this context, hypoxia stands, in the first line, for tissue hypoxia of the two foremost hypoxia-vulnerable organs of the human body, namely the heart and the brain. First of all, it must be stated that the hypoxemia $\left(\mathrm{SaO}_{2}<90 \%\right)$, which the anesthesiologist measures via pulse oximetry during anesthesia and surgery, does not necessarily indicate tissue hypoxia. The cause for a hypoxia is a mismatch between oxygen delivery $\left(\mathrm{DO}_{2}\right)$ to and oxygen consumption $\left(\mathrm{VO}_{2}\right)$ by the human body, a particular tissue or a yet smaller group of cells, respectively.

Relevant hypoxia appears whenever the oxygen demands of those biological units outweigh their actual oxygen supply. The situation is complicated by the fact that oxygen demand is not stable but highly variable and context sensitive, i.e., hypothermia versus hyperthermia or rest versus exercise. Cell death and severe, irreversible tissue damage are the results of prolonged oxygen under-supply of tissues. Especially the adult human myocardial and brain tissues lack almost from any global regenerative potential which makes their perioperative hypoxic damage in particular devastating $[25,26]$. and lower graphs represent systolic and diastolic arterial pressure, black horizontal dashes represent mean arterial pressure) accompanied by tachycardia (blue dots, heart rate). c Repetitive arterial blood gas analyses throughout the procedure including the oxygen content of the arterial blood $\left(\mathrm{CaO}_{2}\right)$

In the context of thoracic surgery, cell oxygen demands depend on several factors like existence of prescribed medication [27, 28], sepsis or systemic inflammation [29], body temperature, and kind and depth of anesthesia [30-33]. Unfortunately, the actual oxygen demand of the body during a thoracic surgical procedure stays largely obscured to the anesthesiologist because appropriate measurement means do not exist for clinical application. How much oxygen reaches the cell rests on the four pillars (I) oxygen transport capacity (blood hemoglobin content), (II) oxygen load of the oxygen carrier (hemoglobin saturation), (III) organ perfusion, and (IV) capillary oxygen partial pressure [34]. Impairments of one or more of these pillars lead to hypoxia, albeit not to a similar extent. Whereas a 50\% reduction of the oxygen transport capacity (anemic anemia) is well tolerated under resting conditions, this is less the case for both a $50 \%$ reduction of the oxygen load of the hemoglobin (hypoxic hypoxia) and the organ perfusion (stagnant hypoxia), respectively. The least well tolerated kind of tissue hypoxia is caused by a direct reduction of the mitochondrial function (cytotoxic hypoxia) by carbon monoxide poisoning for instance [35]. 
For the case that several types of hypoxia exist at the same time, it is important for the anesthesiologist to consider that reductions in oxygen transport do not simply sum up but multiply each other. Reductions of 50\% of the cardiac output, arterial oxygen saturation, and hemoglobin content each may lead to an overall reduction of oxygen delivery to oneeighth [36].

\section{The Tolerable Hypoxic Limits of Healthy, Conscious, Individuals}

For the understanding of the general hypoxemic limits of patients during thoracic surgery, disregarding of any preexisting diseases of these patients, the anesthesiologist can learn substantially from physiological studies of healthy individuals under extreme atmospheric environments [37]. Hypoxia is defined as a decrease of partial pressure of oxygen $\left(\mathrm{pO}_{2}\right.$, $\mathrm{kPa}$, or $\mathrm{mmHg}$ ) in the organ of interest, in contrast to hypoxemia which is the term for only a decrease of blood oxygen content $\left(\mathrm{cO}_{2}, \mathrm{~mL} / \mathrm{dL}\right)$. To define the limits of tissue hypoxia, each organ should be looked at separately. The amount of oxygen delivered by blood to an organ is usually regulated via the perfusion of the organ. In the normoxic steady state of an organ, so called physioxia [38], oxygen delivery equalizes oxygen demands. When the oxygen demand of the organ outweighs oxygen delivery, tissue hypoxia appears [38].

The human brain can be seen as the index organ for the effects of hypoxia on the human body. However, the heart and the diaphragm are two other organs which are characterized by their well-known intolerance to hypoxia [39, 40]. Animal studies suggest that myocardial metabolism in hypoxia is maintained when the arterial oxygen content stays above 8 $\mathrm{mL} / \mathrm{dL}$ [41]. However, sufficient myocardial adaptation to hypoxemia depends greatly on a well-maintained mean arterial pressure [42] and a coronary vasodilatory reserve. The human brain has one of the highest resting oxygen metabolic rates of the organs of the human body $\left(3.5 \mathrm{~mL} \mathrm{O}_{2}\right.$ per $100 \mathrm{~g}$ of brain tissue) but has no relevant oxygen stores available. Normal brain oxygenation can be assumed for cerebral tissue $\mathrm{PO}_{2}$ above $35 \mathrm{mmHg}$ and cerebral blood flow is immediately increased when brain tissue partial pressure of oxygen drops below approximately $30 \mathrm{mmHg}$. At a $\mathrm{SaO}_{2}$ of $70 \%$ and a $\mathrm{PaO}_{2}$ of $35 \mathrm{mmHg}$, respectively, the cerebral metabolism continues to depend almost exclusively on oxidative glucose metabolism without significant lactate accumulation [43]. Remarkably, high altitude mountaineers exceeding $7000 \mathrm{~m}$ are defending an alveolar $\mathrm{PO}_{2}$ of $35 \mathrm{mmHg}$ and avoid a further fall in alveolar oxygen partial pressure by a continuing increase in ventilation [44]. However, coma can result at tissue $\mathrm{PO}_{2}$ levels below $20 \mathrm{mmHg}$ [45].

The healthy, conscious human brain responds to acute hypoxemia via a rise in blood flow, an accelerated ventilator work, and an increase in oxygen extraction [46-48]. Reduced arterial oxygen content with deoxygenated hemoglobin as the primary oxygen sensor acts as chief regulator of cerebral vasodilation [49]. Thus, assuming a normal blood pressure regulation, the healthy human body is able to maintain oxygen delivery to the brain over a wide range of hypoxemia by increasing brain perfusion.

Interestingly, this response is diminished if arterial oxygen content decreases because of a hemodilution-induced fall of hemoglobin concentration instead of actual hypoxemia [49]. Considering that hemodilution is daily practice in thoracic anesthesia, this might influence the hypoxemic limits of the human brain during one-lung ventilation. When hypoxemia challenges the human, at altitude for instance, several defense mechanisms are activated including hyperventilation, shifting of the oxygen dissociation curve, hemoconcentration, and a rise in cardiac output by tachycardia [50]. Through these adaptation mechanisms, highly trained individuals have proven a fascinating high hypoxia tolerance of the human body. High altitude mountaineers were still able to maintain consciousness and elementary physical performance at an inspiratory $\mathrm{PO}_{2}$ of $43 \mathrm{mmHg}$ resulting in a mean $\mathrm{SaO}_{2}$ of only $35 \%$ [51].

Cardiac pump function was preserved in subjects who undertook a simulated climb of Mount Everest in a hypobaric chamber [52]. On the actual top of Mount Everest, the arterial oxygen partial pressure in elite climbers, who returned from the summit without any irreversible neurological sequelae, was calculated as low as $28 \mathrm{mmHg}$ [53]. The lowest ever measured arterial oxygen partial pressure and arterial oxygen saturation in a conscious individual were $19 \mathrm{mmHg}$ and 34\%, respectively, measured at $8400-\mathrm{m}$ altitude during a summit attempt at Mount Everest [54]. Likewise, very low arterial oxygen saturations in healthy humans $(50-70 \%)$ were reached in a protected laboratory environment for the purpose of testing of pulse oximetry devices. During these tests, the participants did not show any circulatory impairment or systemic acidosis [55 $]$. Elite apnea divers, with their lungs filled with room air, were able to stop breathing for up to $435 \mathrm{~s}$ resulting in a decrease of $\mathrm{PaO}_{2}$ and $\mathrm{SaO}_{2}$ to $23 \mathrm{mmHg}$ and $34 \%$, respectively [56.]. In contrast to hypocapnic hypoxemia in mountaineers, apnea divers develop hypercapnic hypoxemia which may better mimic hypoxemia usually seen in patients with chronic obstructive lung disease or obstructive sleep apnea.

\section{The Tolerable Hypoxic Limits of Patients}

It goes without saying that no systematic studies on the limits of hypoxia tolerance of patients or hypoxemic dose-response relationships have been performed due to ethical and safety constraints. The threshold of $\mathrm{SaO}_{2}$ below which a clinically relevant hypoxemia exists has never been clearly investigated. Based on observations in healthy individuals, $\mathrm{SaO} 2$ values between 90 and $75 \%$ have been suggested to be safe 
[57-59]. For example, the current guidelines for adult respiratory failure of the Extracorporeal Life Support Organization (ELSO) accept a hypoxemia with a $\mathrm{SaO}_{2}$ of $75 \%$ if cardiac output and hemoglobin concentration are adequate [60]. The existence of tissue hypoxia has been suggested for the case that blood lactate concentration would rise above $2.2 \mathrm{mmol} / \mathrm{L}$ and central venous oxygen saturation would be less than $70 \%$ [61].

Nevertheless, a situation of intraoperative hypoxemia is difficult to interpret, because peripheral oxygen saturation and arterial oxygen partial pressure seem to have only a weak relation with cerebral oxygenation during one-lung ventilation [62]. Technical limitations of the cerebral near infrared spectroscopy technique may, at least in part, be responsible for this weak relationship and drops in cerebral oxygenation during one-lung ventilation could be less than it has been reported so far $[63,64 \cdot]$. In accordance, a recent study was not able to find a relationship between postoperative cognitive decline and intraoperative cerebral desaturations and the authors question the rationale for avoiding intraoperative decreases in cerebral oxygenation [65]. Further advanced methods to continuously monitor circulation and oxygenation intraoperatively are still not part of clinical routine. In this context, methods for the simultaneous monitoring of parameters of global and local, organ specific parameters of oxygen delivery, oxygen demand, and production of anaerobic metabolites could be a step forward and enable an individualized oxygen therapy. Thus, our actual knowledge on hypoxic limits of patients is small and mainly generated out of clinical outcome experience with patients who suffered therapy refractory hypoxemia, as it is the case in our case report. In a case series of seven patients, no neurological sequelae associated with a therapy with extracorporeal membrane oxygenation and hypoxemia of an average $\mathrm{SaO}_{2}$ of $79 \%$ lasting several days could be found retrospectively [66•]. Although global hypoxic damage of the heart or the brain virtually never happens intraoperatively as long as spontaneous circulation persists, regional hypoxic-ischemic events like stroke or heart attack are common threats [67].

In this regard, it is quite surprising how little is known about the effects on the healthy and diseased heart of hypoxia as opposed to ischemia [40]. Not only macroangiopathic but also microangiopathic diffuse cardiac disease can facilitate myocardial tissue hypoxia [68] but might be easily overlooked during preoperative evaluation. One study elucidating myocardial metabolism under hypoxemia during one-lung ventilation reported no clinically significant signs of myocardial ischemia in patients with multi-vessel coronary disease and drops in arterial partial pressure of oxygen down to levels between 50 and $70 \mathrm{mmHg}$. Therefore, the authors were unable to define a safety margin of tolerable minimal arterial oxygen partial pressure above the anaerobic threshold of the myocardial metabolism [69••]. This safety margin has to be considered to be clearly patient dependent. The myocardium of aged humans, for instance, showed a reduced tolerance to ischemia and hypoxia [70]. Low left ventricular ejection fraction and high pulmonary vascular resistance were predictors for hypoxic events $\left(\mathrm{PaO}_{2}<70 \mathrm{mmHg}\right)$ in patients undergoing robotassisted coronary artery bypass grafting and requiring continuous OLV [71]. Several patient trials are currently underway to find a better answer on the question of the "best oxygen content" and if hypoxemia really matters $[65,72,73]$.

\section{Conclusions}

Hypoxemia $\left(\mathrm{SaO}_{2}<90 \%\right)$ happens regularly during anesthesia with a one-lung ventilation technique. Because of a lack of adequate, clinical measurement methods, the anesthesiologist is not able to instantaneously decide whether an intraoperative hypoxemia really matters in terms of the simultaneous existence of a relevant hypoxia of vital organs, like the brain or the heart. This is one of the reasons why the outcome of the patients with intraoperative desaturations during OLV has not been systematically studied yet. Although the healthy, conscious individual with a functioning cardiopulmonary system has a relatively high hypoxemia tolerance, the thoracic anesthesiologist cannot assume a similar hypoxemia tolerance for the majority of his patients undergoing thoracic surgery. Preexisting conditions like chronic heart failure, coronary or cerebral arterial disease, and anemia on the one hand, and the effects of surgery, anesthesia, and mechanical ventilation on the other, may prevent these patients to develop an appropriate physiological response to intraoperative hypoxemic stress. Nevertheless, a high hypoxemia tolerance has also been reported for certain patients, for instance individuals receiving an extracorporeal membrane oxygenation therapy.

The reverse, a too liberal intraoperative oxygen therapy leads to oxygen stress and may either harm the patient directly or boost the surgical induced inflammatory response syndrome. The intention of any oxygen therapy should be therefore the avoidance of a relevant tissue hypoxia, instead to simply treat the "symptom" hypoxemia. From this point of view, the lowest possible intraoperative oxygen therapy would be considered desirable. Though, the question if hypoxemia during one-lung ventilation really matters cannot be finally answered yet. So far, it can be concluded that moderate hypoxemia $\left(\mathrm{SaO}_{2} 90-75 \%\right)$ is tolerable by and maybe even useful in certain patients. However, better studies are urgently needed to investigate an individual "best oxygen content" concept for each patient receiving one-lung ventilation.

\section{Compliance with Ethical Standards}

Conflict of Interest Ulrich Limper and Burkhard Hartmann declare they have no conflict of interest. 
Human and Animal Rights and Informed Consent This article does not contain any studies with human or animal subjects performed by any of the authors.

\section{References}

Papers of particular interest, published recently, have been highlighted as:

- Of importance

•- Of major importance

1. Ahn S, Moon Y, AlGhamdi ZM, Sung SW. Nonintubated uniportal video-assisted thoracoscopic surgery: a single-center experience. Kor J Thor Cardiovasc Surg. 2018;51(5):344-9.

2. Elkhayat H, Gonzalez-Rivas D. Non-intubated uniportal videoassisted thoracoscopic surgery. J Thor Dis. 2019;11(Suppl 3): S220-s2.

3. Torda TA, McCulloch CH, O'Brien HD, Wright JS, Horton DA. Pulmonary venous admixture during one-lung anaesthesia. The effect of inhaled oxygen tension and respiration rate. Anaesthesia. 1974;29(3):272-9.

4.• Karzai W, Schwarzkopf K. Hypoxemia during one-lung ventilation: prediction, prevention, and treatment. Anesthesiology. 2009;110(6):1402-11 This study is the most cited one when the incidence of hypoxemia during one-lung ventilation is given.

5. Campos JH, Feider A. Hypoxia during one-lung ventilation-a review and update. J Cardiothorac Vasc Anesth. 2018;32(5):2330-8 This is the most recent review on hypoxia during one-lung ventilation.

6. Tripathi RS, Papadimos TJ. Life-threatening hypoxemia in onelung ventilation. Anesthesiology. 2011;115(2):438 author reply 941.

7. Morkane CM, McKenna H, Cumpstey AF, Oldman AH, Grocott MPW, Martin DS. Intraoperative oxygenation in adult patients undergoing surgery (iOPS): a retrospective observational study across 29 UK hospitals. Perioperative medicine (London, England). 2018:7:17.

8. Benatar SR, Hewlett AM, Nunn JF. The use of iso-shunt lines for control of oxygen therapy. Br J Anaesth. 1973;45(7):711-8.

9. Russell WJ. Intermittent positive airway pressure to manage hypoxia during one-lung anaesthesia. Anaesth Intensive Care. 2009;37(3):432-4.

10. Russell WJ. Hypoxemia during one-lung ventilation: looking the other way. Anesthesiology. 2011;115(2):437 author reply 9-41.

11. Russell WJ. Hypoxaemia associated with one-lung anaesthesia: an alternative approach. Br J Anaesth. 2011;107(5):818 author's reply.

12. Kremer R, Aboud W, Haberfeld O, Armali M, Barak M. Differential lung ventilation for increased oxygenation during one lung ventilation for video assisted lung surgery. J Cardiothorac Surg. 2019;14(1):89.

13.• Brugniaux JV, Coombs GB, Barak OF, Dujic Z, Sekhon MS, Ainslie PN. Highs and lows of hyperoxia: physiological, performance, and clinical aspects. Am J Physiol Regul Integr Comp Physiol. 2018;315(1):R1-r27 A very comprehensive review of the actions of hyperoxia.

14. Heerdt PM, Lane PB, Crabtree MJ, Park BJ. Systemic oxidative stress associated with lung resection during single lung ventilation. Eur J Cardio-Thor Surg. 2006;30(3):568-9.

15. Misthos P, Katsaragakis S, Theodorou D, Milingos N, Skottis I. The degree of oxidative stress is associated with major adverse effects after lung resection: a prospective study. European journal of cardio-thoracic surgery : official journal of the European Association for Cardio-thoracic Surgery. 2006;29(4):591-5.

16. Roberts SM, Cios TJ. Con: Hyperoxia should not be used routinely in the management of cardiopulmonary bypass. J Cardiothorac Vasc Anesth. 2019;33(7):2075-8.

17. Lavie L. Oxidative stress in obstructive sleep apnea and intermittent hypoxia-revisited-the bad ugly and good: implications to the heart and brain. Sleep Med Rev. 2015;20:27-45 This study is one out of only a few which gives a balanced description of both bad and beneficial aspects of oxygen stress.

18. Meyhoff CS, Jorgensen LN, Wetterslev J, Christensen KB, Rasmussen LS. Increased long-term mortality after a high perioperative inspiratory oxygen fraction during abdominal surgery: follow-up of a randomized clinical trial. Anesth Analg. 2012;115(4):849-54.

19. Staehr-Rye AK, Meyhoff CS, Scheffenbichler FT, Vidal Melo MF, Gatke MR, Walsh JL, et al. High intraoperative inspiratory oxygen fraction and risk of major respiratory complications. Br J Anaesth. 2017;119(1):140-9.

20. Lohser J, Slinger P. Lung injury after one-lung ventilation: a review of the pathophysiologic mechanisms affecting the ventilated and the collapsed lung. Anesth Analg. 2015;121(2):302-18.

21. Heerdt PM, Stowe DF. Single-lung ventilation and oxidative stress: a different perspective on a common practice. Curr Opin Anaesthesiol. 2017;30(1):42-9.

22. Pak O, Sydykov A, Kosanovic D, Schermuly RT, Dietrich A, Schroder K, et al. Lung ischaemia-reperfusion injury: the role of reactive oxygen species. Adv Exp Med Biol. 2017;967:195-225.

23. Brettner F, von Dossow V, Chappell D. The endothelial glycocalyx and perioperative lung injury. Curr Opin Anaesthesiol. 2017;30(1): 36-41.

24. Suzuki S, Mihara Y, Hikasa Y, Okahara S, Ishihara T, Shintani A, et al. Current ventilator and oxygen management during general anesthesia: a multicenter, cross-sectional observational study. Anesthesiology. 2018;129(1):67-76 This reference gives the current practice of oxygen therapy in single lung ventilation procedures.

25. Kimura W, Nakada Y, Sadek HA. Hypoxia-induced myocardial regeneration. J Appl Physiol (1985). 2017;123(6):1676-81.

26. Adams KL, Gallo V. The diversity and disparity of the glial scar. Nat Neurosci. 2018;21(1):9-15.

27. Lin A, Maity A. Molecular pathways: a novel approach to targeting hypoxia and improving radiotherapy efficacy via reduction in oxygen demand. Clinical cancer research : an official journal of the American Association for Cancer Research. 2015;21(9):19952000.

28. Vermeulen TD, Boulet LM, Stembridge M, Williams AM, Anholm JD, Subedi P, et al. Influence of myocardial oxygen demand on the coronary vascular response to arterial blood gas changes in humans. Am J Physiol Heart Circ Physiol. 2018;315(1):H132-h40.

29. Arulkumaran N, Deutschman CS, Pinsky MR, Zuckerbraun B, Schumacker PT, Gomez H, et al. Mitochondrial function in sepsis. Shock. 2016;45(3):271-81.

30. Doe A, Kumagai M, Tamura Y, Sakai A, Suzuki K. A comparative analysis of the effects of sevoflurane and propofol on cerebral oxygenation during steep Trendelenburg position and pneumoperitoneum for robotic-assisted laparoscopic prostatectomy. J Anesth. 2016;30(6):949-55.

31. Garutti I, Quintana B, Olmedilla L, Cruz A, Barranco M. Garcia de Lucas E. Arterial oxygenation during one-lung ventilation: combined versus general anesthesia. Anesth Analg. 1999;88(3):494-9.

32. Iwata M, Inoue S, Kawaguchi M, Takahama M, Tojo T, Taniguchi $\mathrm{S}$, et al. Jugular bulb venous oxygen saturation during one-lung ventilation under sevoflurane- or propofol-based anesthesia for lung surgery. J Cardiothorac Vasc Anesth. 2008;22(1):71-6. 
33. Von Dossow V, Welte M, Zaune U, Martin E, Walter M, Ruckert J, et al. Thoracic epidural anesthesia combined with general anesthesia: the preferred anesthetic technique for thoracic surgery. Anesth Analg. 2001;92(4):848-54.

34. Barcroft J. Physiological effects of insufficient oxygen supply*. Nature. 1920;106(2656):125-9.

35. Limper U. Die akute Kohlenmonoxidintoxikation - ein aktueller Überblick über die Pathophysiologie und die intensivmedizinische Therapie. Jahrbuch Intensivmedizin 2018. Jahrbuch Intensivmedizin. Lengerich: Pabst Science Publishers; 2018. p. 159-94.

36. Lumb AB, Nunn JF. Nunn's applied respiratory physiology. 6th ed. Edinburgh ; Philadelphia: Elsevier Butterworth Heinemann; 2005. xiii, 501 p. p

37. Grocott M, Montgomery H, Vercueil A. High-altitude physiology and pathophysiology: implications and relevance for intensive care medicine. Crit Care. 2007;11(1):203.

38. Carreau A, El Hafny-Rahbi B, Matejuk A, Grillon C, Kieda C. Why is the partial oxygen pressure of human tissues a crucial parameter? Small molecules and hypoxia. J Cell Mol Med. 2011;15(6):123953.

39. Lewis P, O'Halloran KD. Diaphragm muscle adaptation to sustained hypoxia: lessons from animal models with relevance to high altitude and chronic respiratory diseases. Front Physiol. 2016;7:623.

40. Davies SW, Wedzicha JA. Hypoxia and the heart. Br Heart J. 1993;69(1):3-5.

41. Hackel DB, Goodale WT, Kleinerman J. Effects of hypoxia on the myocardial metabolism of intact dogs. Circ Res. 1954;2(2):169-74.

42. Mechelinck M, Hein M, Bellen S, Rossaint R, Roehl AB. Adaptation to acute pulmonary hypertension in pigs. Physiological reports. 2018;6(5).

43. Ainslie PN, Shaw AD, Smith KJ, Willie CK, Ikeda K, Graham J, et al. Stability of cerebral metabolism and substrate availability in humans during hypoxia and hyperoxia. Clinical science (London, England : 1979). 2014;126(9):661-70.

44. West JB. Human responses to extreme altitudes. Integr Comp Biol. 2006;46(1):25-34.

45. Hall J. Guyton and Hall textbook of medical physiology 13th Edition, Chapter 62 Cerebral blood flow, cerebrospinal fluid, and brain metabolism. USA: Elsevier; 2015.

46. Liu X, Xu D, Hall JR, Ross S, Chen S, Liu H, et al. Enhanced cerebral perfusion during brief exposures to cyclic intermittent hypoxemia. J Appl Physiol (1985). 2017;123(6):1689-97.

47. Koch A, Kahler W, Klapa S, Kuhtz-Buschbeck JP. Maintaining cerebral oxygen homeostasis: a serious business. Clin Auton Res. 2018;28(4):395-6.

48. Hoiland RL, Howe CA, Coombs GB, Ainslie PN. Ventilatory and cerebrovascular regulation and integration at high-altitude. Clin Auton Res. 2018;28(4):423-35.

49. Hoiland RL, Bain AR, Rieger MG, Bailey DM, Ainslie PN. Hypoxemia, oxygen content, and the regulation of cerebral blood flow. Am J Physiol Regul Integr Comp Physiol. 2016;310(5): R398-413.

50. Naeije R. Physiological adaptation of the cardiovascular system to high altitude. Prog Cardiovasc Dis. 2010;52(6):456-66.

51. Cymerman A, Reeves JT, Sutton JR, Rock PB, Groves BM, Malconian MK, et al. Operation Everest II: maximal oxygen uptake at extreme altitude. J Appl Physiol (1985). 1989;66(5):2446-53.

52. Reeves JT, Groves BM, Sutton JR, Wagner PD, Cymerman A, Malconian MK, et al. Operation Everest II: preservation of cardiac function at extreme altitude. J Appl Physiol (1985). 1987;63(2): 531-9.

53. West JB, Hackett PH, Maret KH, Milledge JS, Peters RM Jr, Pizzo CJ, et al. Pulmonary gas exchange on the summit of Mount Everest. J Appl Physiol Respir Environ Exerc Physiol. 1983;55(3):678-87.
54. Grocott MP, Martin DS, Levett DZ, McMorrow R, Windsor J, Montgomery HE, et al. Arterial blood gases and oxygen content in climbers on Mount Everest. N Engl J Med. 2009;360(2):140-9.

55. Bickler PE, Feiner JR, Lipnick MS, Batchelder P, MacLeod DB, Severinghaus JW. Effects of acute, profound hypoxia on healthy humans: implications for safety of tests evaluating pulse oximetry or tissue oximetry performance. Anesthesia and analgesia. 2017;124(1):146-53 This recent study shows that healthy, conscious individuals withstand short phases of severe hypoxemia without harm.

56. Bailey DM, Willie CK, Hoiland RL, Bain AR, MacLeod DB, Santoro MA, et al. Surviving without oxygen: how low can the human brain go? High altitude medicine \& biology. 2017;18(1): 73-9 This review summarizes the current knowledge on the tolerable hypoxia limits of the human brain.

57. O'Driscoll BR, Howard LS, Earis J, Mak V. BTS guideline for oxygen use in adults in healthcare and emergency settings. Thorax. 2017;72(Suppl 1):ii1-ii90.

58. Zander R, Mertzlufft F. Therapeutische Grenzwerte der akuten, arteriellen Hypoxie. AINS-Anästhesiologie- IntensivmedizinNotfallmedizin. Schmerztherapie. 1996;31(06):372-4.

59. Zander R, Mertzlufft F. The oxygen status of arterial blood: S Karger Pub; 1991.

60. (ELSO) ELSO. Guidelines of the Extracorporeal Life Support Organization (ELSO) for adult respiratory failure 2017 [Available from: https://www.elso.org/Resources/Guidelines.aspx.]

61. Sevuk U, Altindag R, Baysal E, Yaylak B, Adiyaman MS, Akkaya $\mathrm{S}$, et al. The effects of hyperoxaemia on tissue oxygenation in patients with a nadir haematocrit lower than $20 \%$ during cardiopulmonary bypass. Perfusion. 2016;31(3):232-9.

62. Hemmerling TM, Bluteau MC, Kazan R, Bracco D. Significant decrease of cerebral oxygen saturation during single-lung ventilation measured using absolute oximetry. Br J Anaesth. 2008;101(6): $870-5$.

63. Kato S, Yoshitani K, Kubota Y, Inatomi Y, Ohnishi Y. Effect of posture and extracranial contamination on results of cerebral oximetry by near-infrared spectroscopy. J Anesth. 2017;31(1):103-10.

64. Tanaka N, Katoh RI, Yamamoto M, Hoshino K, Morimoto Y, Ito YM, et al. Changes in cerebral oxygen saturation during one-lung ventilation determined using spatially resolved spectroscopy and contributing factors. Journal of clinical anesthesia. 2019;59:99100 The technical limitations and pitfalls of the cerebral infrared spectroscopy method applied during one-lung ventilation procedures are discussed.

65. Shaefi S, Marcantonio ER, Mueller A, Banner-Goodspeed V, Robson SC, Spear K, et al. Intraoperative oxygen concentration and neurocognition after cardiac surgery: study protocol for a randomized controlled trial. Trials. 2017;18(1):600.

66. Holzgraefe B, Andersson C, Kalzen H, von Bahr V, Mosskin M, Larsson EM, et al. Does permissive hypoxaemia during extracorporeal membrane oxygenation cause long-term neurological impairment?: A study in patients with H1N1-induced severe respiratory failure. Eur J Anaesthesiol. 2017;34(2):98-103 This reference is one of only a few that report good neurological outcome in patients who had suffered sustained severe hypoxemia.

67. Shyamsundar M, O'Kane C, Perkins GD, Kennedy G, Campbell C, Agus A, et al. Prevention of post-operative complications by using a HMG-CoA reductase inhibitor in patients undergoing one-lung ventilation for non-cardiac surgery: study protocol for a randomised controlled trial. Trials. 2018;19(1):690.

68. Richard CC. Myocardial ischemia is not always due to epicardial atheromatous disease. Clin Cardiol. 2011;34(1):8-9.

69.• Mierdl S, Meininger D, Dogan S, Wimmer-Greinecker G, Westphal K, Bremerich DH, et al. Does poor oxygenation during one-lung ventilation impair aerobic myocardial metabolism in patients with symptomatic coronary artery disease? Interactive 
Cardiovasc Thor Surg. 2007;6(2):209-13 This reference gives actual intraoperative data on myocardial oxygen metabolism with respect to hypoxia.

70. Mariani J, Ou R, Bailey M, Rowland M, Nagley P, Rosenfeldt F, et al. Tolerance to ischemia and hypoxia is reduced in aged human myocardium. J Thorac Cardiovasc Surg. 2000;120(4):660-7.

71. Liu TJ, Shih MS, Lee WL, Wang KY, Liu CN, Hung CJ, et al. Hypoxemia during one-lung ventilation for robot-assisted coronary artery bypass graft surgery. Ann Thorac Surg. 2013;96(1):127-32.

72. Lopez MG, Pretorius M, Shotwell MS, Deegan R, Eagle SS, Bennett JM, et al. The Risk of Oxygen during Cardiac Surgery
(ROCS) trial: study protocol for a randomized clinical trial. Trials. 2017;18(1):295.

73. Martin DS, Brew-Graves C, McCartan N, Jell G, Potyka I, Stevens $\mathrm{J}$, et al. Protocol for a feasibility randomised controlled trial of targeted oxygen therapy in mechanically ventilated critically ill patients. BMJ Open. 2019;9(1):e021674.

Publisher's Note Springer Nature remains neutral with regard to jurisdictional claims in published maps and institutional affiliations. 